\title{
Pre-service Teachers' Probabilistic Reasoning in Constructivist Classroom
}

\author{
Evans Kofi Hokor ${ }^{1 *}$
}

${ }^{1}$ St. Teresa's College of Education, Hohoe, GHANA

*Corresponding Author: evanskhokor@gmail.com

Citation: Hokor, E. K. (2020). Pre-service Teachers' Probabilistic Reasoning in Constructivist Classroom. Pedagogical Research, $5(2)$, em0053. https://doi.org/10.29333/pr/7838

ARTICLE INFO

Received: 25 Feb. 2020

Accepted: 25 Feb. 2020

\begin{abstract}
Several studies revealed that probability misconceptions were widespread among students, but the activities for addressing the misconceptions has been lacking. This study designed activities that reflect real life situations for addressing equiprobability bias, positive and negative recency effects, belief bias and representativeness bias for teaching probability globally. Thirty-two pre-service teachers from one intact class were purposively sampled for the study. The instruments used in the collection of data were observation and questionnaire. The study found constructivist approach of teaching with critical questions asked by the teacher to be vital in addressing misconceptions. The findings suggest that teacher educators should use the constructivist approach of teaching targeting probabilistic misconceptions in training of teachers.
\end{abstract}

Keywords: mathematics education, teacher education, teaching probability, assessment, probabilistic reasoning

\section{INTRODUCTION}

The study of probability throughout the world remains important to every nation because of many uncertain situations around us. Success in any form of education and training and in all fields of human endeavor worldwide depends largely upon the ability of the individual to make informed choices. Probability is one of the most essential concepts of our life since it equipped us to make better choices. No matter which field you belong to, you cannot run away from its uses. Irrespective of the language you speak or country you live in, the uses of probability remain essential tool in decision making, and to that extent transformation of society. Both young and old are confronted with uncertain situations daily, in such environment the importance of good probabilistic reasoning can never be underestimated.

In order for pre-service teachers to understand what they learn and apply, the Statistics curriculum across nations recommended activity-based teaching (Batanero \& Diaz, 2012; Gage, 2012). The Statistics and Probability curriculum for colleges of education requires teachers to place pre-service teachers at the centre of the teaching and learning process if they are to teach probability units effectively at the basic schools. The evidence suggests that the Statistics curriculum is based on the principle of constructivism since it provides learners with opportunities to learn from their own experiences. Godino, Batanero and Roa (2001, p. 2) cited Even \& Lappan (1994) contends that "if we want teachers to follow a constructivist approach in their teaching, we should also use this same approach throughout their training". Shay (2008) argued in support of constructivist approach of teaching probability that "one can only hope that pre-service teachers everywhere have opportunities like this to work through problems and confront their misconceptions, lest they bring these misconceptions into the classroom" (p.33). Similarly, Batanero and Borovcnik (2016) observed that statistics and probability have special characteristics as such require special attention on the part of teachers and curriculum designers in relation to selection context and the best way to make the statistical ideas accessible to the students.

Batanero and Diaz (2012) observed that even when many pre-service teachers for high schools have majored in Mathematics, they usually study only theoretical statistics and probability in their training. This made it difficult for many basic school teachers to teach probability effectively for the understanding of their learners. Similarly, Khazanov and Prado (2010, p. 24) quoted Khazanov (2005, 2008); Konald (1995) and argued that misconceptions about probability do not disappear as a result of traditional instruction in probability. The traditional instructions of probability forces pre-service teachers to become observant and receivers. Because of this, pre-service teachers are unable to reason correctly about probabilistic situations. Shay (2008) underscores the importance of "research that traces individual and group thinking during instruction will give insight into the evolution of probabilistic intuitions and misconceptions" (p.52). This study will provide insight of students' reasoning about 
uncertainties when constructivist approach is used. To develop better probabilistic reasoning in students, teachers' correct knowledge about probability is needed, most especially teachers who are the first to introduce probability formally to students. These teachers will be in better position to lead students to confront any misconceptions they bring to classroom and deal with it at that stage.

Even though all the studies agreed on the constructivist approach of teaching probability, there's general lack of activities in helping students develop correct probabilistic reasoning. The calls for constructivist approach of teaching probability is great but not enough if we fail to provide activities that reflect real life situations for acquisition of the necessarily skills for decision making. Furthermore, the role of critical questions in constructivist approach of teaching has not been well documented. This paper intend to address the above concerns by providing teachers with rich real life activities in teaching probability. Also, construct a model that foster conceptual understanding. In addition, this study grew out of inadequate activities in addressing probabilistic misconceptions and classroom reality of how students reason about uncertainties. Furthermore, several studies calls for assessment of students' probabilistic reasoning in instructional approaches that target probabilistic misconceptions (Godino, Batanero, \& Roa, 2001; Khazanov \& Prado, 2010; Liu, 2005). Additionally, in spite of many calls for constructivist approach of teaching, there is in general a lack of insight into what should be done in the transmission of statistical knowledge in classroom setting. This study provide that great insight. The next section present the theoretical framework of the study.

\section{THEORETICAL FRAMEWORK OF THE STUDY}

This study was based on the constructivist's theory of teaching and learning. In a constructivist classroom, knowledge move from teacher to student, student to student, and student to teacher randomly. The learners are motivated and engaged in the teaching and learning processes to construct ideal meaning of concepts. Human beings have no access to an objective reality, and that reality is independent of our way of knowing; an ideal of constructivism philosophy. We construct our knowledge of our world from experiences. In this $21^{\text {st }}$ century, "knowledge should represent a 'real' world that is thought of as 'existing' separate and independent of the knower; and this knowledge should be considered 'true' only if it correctly reflects that independent world" (von Glasersfeld, 1995, p.3). In this study, a constructivist learning intervention provides learners with the opportunity to discover and develop good understanding of concepts through activities, and this reflect the independent world. Many teachers are of the view that students build their knowledge in an active way by solving problems and interacting with their friends or classmates.

Constructivists hold the view that students bring to class their own ideas. And teachers only need to guide them with manipulatives to reorganize the new information to fit into cognitive frameworks. In this case the focus is on students' conceptual understanding. What are the skills and ideas teachers would expect their learners to acquire in probability? These goals are not mostly reflected on their assessment items such as quizzes, tests, and examinations. Suppose teachers were asked what they want pre-service teachers to know after one or two years after completing their probability units, many of them may not respond that pre-service teachers should be able to calculate the probability of independent events or conditional probability. Most of the teachers may say they want their students to understand basic probability concepts and ideas to make a good decisions in life.

\section{The Need for Correct Probabilistic Reasoning}

Probabilistic reasoning refers to the way people reason about uncertain situations and making decisions based on the likely outcomes. Randomness and uncertainties are frequent in our daily lives and having a sound understanding about probability helps make inform choices of these uncertainties. The study of probability enlightens us to make informed judgments about what is most likely to occur after considering all the possibilities. Probability empowered us to make better decisions while still not forgotten that our decision may not necessarily result in the way we consider it fit. Weather forecasters study a pattern of data collected on rainfall and estimate the chance or the likelihood of rainfall on particular days or periods. Knowing whether there will be a rainfall on a particular day informs us on what to do or not. For example, whether to go to farm or not. It also helps decide on when to wash our cloths for the purpose of drying.

Furthermore, the knowledge of probability is applied in insurance policy. Probabilistic reasoning makes it clear why policyholders contracting similar insurance policies may have different rating. The insurers examine the risk factors associated with each insurance holder to arrive at the premium rates. Probability reveals, the chance of some individuals filing claims are higher than others as such the premium rate is directly proportional to the risk. The property and liability that Insurance companies provide are based on the use of probability to assess risks. In insurance, the age and gender of the driver determine the possibility that an accident may happen or not. The kind of vehicle insured, the location of the policyholder are important factors to arrive at premium rates. The more miles policyholder drives, the higher the chance of getting accident. Understanding of probability helps appreciate things around us and makes life meaningful.

\section{Mathematical Reasoning versus Probabilistic Reasoning}

The theories of probability can mostly be explained but cannot be proved as is the case in various branches of Mathematics such as Geometry, Algebra, and so on, in their introduction stages. Example, in teaching subtraction, it is easily verified that $9-4$ $=5$ is true by taking four objects from nine objects and count the number of objects left to get five. However, this proving method is not always possible in probability. For example, we have in a bag 12 white balls and 8 yellow balls all are identical in size and material. If you pick a ball at random without replacement six times and it all resulted in yellow balls, this contradicts our initial assumption that we are more likely to pick white balls. Another example, in algebra one can predict the next terms by carefully studying the pattern of numbers like $2,4,6,8,10,12,14 \ldots$ one can say the next number will also be even but this is not the case in probability. In probability, if the toss of a coin five times resulted in five consecutive tails, it does not mean the sixth toss will 
necessary be a tail: is itself counter intuitive. That toss of the coin cannot also be reversed to produce the same results under the same condition is difficult for students to understand. Also, the fact that all numbers on a die has equal chance of occurring does not in itself mean that when a die is rolled 6 times each number on the die must occur defeat mathematical reasoning.

The sum of the first three consecutive positive even numbers is $12=3(3+1)$. The sums of the first four consecutive positive even numbers is $20=4(4+1)$. The sum of the first five consecutive positive even number is $30=5(6+1)$. The sum of the first six consecutive even numbers is $42=6(6+1)$. The sum of the first seven consecutive positive even numbers is $56=7(7+1)$. Therefore, the sum of the first nth consecutive positive even numbers is given by $n(n+1)$. However, if a coin and a die are to be tossed 6 times, and if the first four tossed resulted in multiples of 2 on a die and a head or a tail on the coin is not a guarantee that the rest will also result in multiples of 2 on a die and a head or a tail does not follow the fundamental reasoning of algebra. This is because the tossing of a coin and a rolling of a die are all independent. That is, the occurrence of the first event in no way has any material effect on the occurrence of the second event.

As mathematical reasoning seeks to give us an exact value, probabilistic reasoning on the other hands helps us to understand the uncertainty things in life, and to be mindful of our decisions. Probabilistic reasoning differs from mathematical reasoning, but both of them are sacrosanct for $21^{\text {st }}$ century society and supporting each other in various ways that is helpful in the overall attainment of Mathematics curriculum objectives. Right from the basic probability, the kind of reasoning used are sometimes not intuitive, so if not well taught in the classroom students will miss uncertainty aspect of life. The essence of Mathematics is to help solve real life problems, and probability does not only reflect that but also helps us understand things around us.

\section{PURPOSE OF THE STUDY}

The purpose of this study is to provide assessment of constructivist approach of teaching probability targeting the equiprobability bias, positive and negative recency effects, belief and representativeness bias. The reason for targeting the above misconceptions was that they were wide spread (Ang and Shahrill, 2014; Khazanov \& Prado, 2010; Rubel, 2007; Hirsh \& O'Donnell, 2001). This study add to the existing literature new activities for addressing probability misconceptions. Based on the purpose, the research question that guide and direct this study is: How can teaching and learning be structured to help pre-service teachers develop correct probabilistic reasoning? The answer to this question will help determine the role of constructivist approach of teaching targeting misconceptions on pre-service teachers' reasoning on an uncertainties.

\section{METHODOLOGY}

The research design used in this study is qualitative research design. This design seek to answer the how and why of the phenomenon of interest (Vanderstoep \& Johnsonston, 2009). The designed experiment of the researcher was implemented for four weeks. Classroom lessons were videotaped for the purpose of assessing students' reasoning in the process of constructivist approach of teaching. The pre-service teachers study probability once in every week in two hours. Four students were identified after careful assessment of the lessons videotaped to be inconsistent in their reasoning about random events. The questionnaire was administered to these four participants to express their view and experience on learning probability after constructivist approach of teaching. However, only two participants returned the questionnaire. There were four items on the questionnaire. The questionnaire was developed by the researcher. The purpose of the questionnaire is to provide students' perspective on the impact of the activities.

\section{Sample and Sampling Procedure}

Thirty-two female pre-service teachers in level 200 from one intact class were purposively sampled for the study. The class was selected because all the participants are regular pre-service teachers who have studied probability previously and are taking Statistics and Probability as a Course in a College of Education in second semester of second year studies. One major reason for considering pre-service teachers is that a well equip teachers will be able to teach probability effectively to their learners since no one give what he/she doesn't has.

"Instruction in probability should provide experiences during which students have the opportunity to confront their misconceptions and to develop understandings based on probabilistic thinking" (Sharma, 2016, p. 127). The next sections that follow presents the descriptions of the activities.

\section{Descriptions of Activity One and Classroom Discussions}

This game was played in a group. Four pre-service teachers were in each group. The purpose of this activity is to enhance preservice teachers' understanding of randomness and to address representativeness bias, belief, and positive and negative recency effects. Before the start of the game pre-service teachers were asked which number on the die they think will be the possible outcome when the die is toss. The aim of predicting before the toss was to keep student focus and to confront any prior misconceptions. Almost every student said they can't tell. When asked why. They said any of the numbers is possible. They were asked to roll a die five times and write down the sequence of numbers of their results. When asked what would be the outcome if the die is rolled the six times.

Students 01: "I expect a 5 or a 1 or a 6 ." When asked, why? She said "the previous results were 4, 3, 3, 2, 3, so I expect a 5 or a 1 or a 6 now." The student further added that "since a 5 or a 1 or a 6 has not occurred yet, I am sure one of them will occur." This student had negative recency effect. The response further suggest as if the die has a memory and will naturally balance. 
Student 20: Said she expected a 2. This student had all her previous sequences of her as 2 . The student stressed that "the chance of getting a 2 is high because 2 seem to be very lucky today." This reasoning is called positive recency effect.

For example, students (30, 7, and 21) with the sequences 61253 think that it's time to obtain a 4 in the next toss.

Some pre-service teachers hold the view that getting a 6 is difficult. As such they see the groups that had two 6 or more to be bias. Their credibility was questioned. Some pre-service teachers describe those groups as lucky groups. Student 10: "Getting a 6 is encouraging because 6 is the larger number." One possible explanation for this is that many students focus mostly on getting a 6 than the rest of the numbers. This high expectation for a 6 made them to think that it is difficult to get.

Many students raise a similar argument. Their arguments are based on the sequences of the five outcomes. These pre-service teachers do not see the rolling of the die as independent anymore but think the die will balance naturally. One correct response to a question should not be interpreted to mean a good understanding since many students' are not consistent with their reasoning.

However, a few students said any of the numbers is possible. These pre-service teachers have been consistent with their responses showing good understanding of randomness.

In the next activity, each was asked to write down her prediction for rolling a die six times based on the previous outcome. Each of the students rolled the die and group mate observed and wrote the sequence of her results. At the end of the game, students compared their results to their prediction and found that their results were different from their prediction. After much discussions on the activities most students now realized that the numbers on the die are all equally likely and independent.

Pre-service teachers' understanding of randomness must be tested with a lot of activities. The realization by the students indicates when learners are made to predict before a toss they are able to confront representativeness bias, belief bias, positive and negative recency effects and deal with it. Also, when questions are asked consistently based on their prediction and results, students are able to test their belief and address any misconceptions they bring to class. Furthermore, the participants noted that the number of times the coin was toss by each individual was too small for each number on the die to occur equally.

\section{Description of Activity Two and Classroom Discussion}

The aim of this activity is to guide students to list a sample space. The purpose of this activity is to improve their understanding of a sample space and basic ideas of probability. Each pre-service teacher was given two coins to toss once. Before the toss, they were asked to predict the number of possible outcomes. Many pre-service teachers applied commutative propriety of multiplication by saying when two coins are tossed the possible outcomes are HH, HT, TT or HH, TH, TT. They argued that "only three ways are possible because the sample point $\mathrm{HT}$ is same as $\mathrm{TH}$ " according to communicative property of multiplication. These pre-service teachers failed to see each sample point as combination.

However, some of the few pre-service teachers who listed the sample space as HH, HT, TH, and TT; said they were confused after listening to their colleagues. Some still maintain that their sample space is correct because HT and TH are not same based on the idea of combination. After the activity, teacher organized the whole class discussion around their predictions.

After several experiments link with contingency tables the participants were all successful in listing the sample space as

\begin{tabular}{|c|c|c|}
\hline & $\mathrm{H}$ & $\mathrm{T}$ \\
\hline $\mathrm{H}$ & $\mathrm{HH}$ & $\mathrm{HT}$ \\
\hline $\mathrm{T}$ & $\mathrm{TH}$ & $\mathrm{TT}$ \\
\hline
\end{tabular}

When pre-service teachers were asked to make a choice between tossing "two coins once" and "one coin twice" as to which of them gives better chance of obtaining two heads. Many pre-service teachers opted for tossing one coin twice with the reasons that the first outcome would inform how the second one would be tossed. They further added that the two coins are likely to hit one another and land in a way they do not expect. This explanation indicates a random variable can be controlled based on the way it's thrown. However, the pre-service teachers who prefer tossing two coins once argue that they are often lucky for their first toss.

Moreover, when they tossed the "two coins once" and "one coin twice" they realized the results did not necessary affirm their position. About $96 \%$ of the pre-service teachers now conclude that tossing two coins once is the same as tossing one coin twice. But $4 \%$ of the pre-service teachers hold the view that they are lucky when they tossed "one coin once". However, all the pre-service teachers agree that there are four possible outcomes when you toss "two coins once" or "one coin twice" and the chance of getting two heads is same in each case.

The growing evidence provide support for multiple representation in teaching probability, particularly listing of sample space using contingency tables, and tree diagrams.

\section{Example on Sample Space}

A new couple plan to have three children, suppose each child to be born has equal chance of being a boy (B) or a girl (G). What are the possible ways they can have children? What is the probability of the couple having exactly children of two sex? The preservice teachers were quick in listing the sample space using contingency tables as

\begin{tabular}{|c|c|c|c|c|}
\hline & BB & BG & GB & GG \\
\hline B & BBB & BBG & BGB & BGG \\
\hline G & GBB & GBG & GGB & GGG \\
\hline
\end{tabular}

Some pre-service teachers also used tree diagrams to list the sample space. 
The probability of couple having exactly children of two sex is $\frac{6}{8}=\frac{3}{4}$

Pre-service teachers are able to adopt and apply strategy to list possible outcomes in two-stage and three-stage cases consistently. This imply we should present students with multiple approach for solving probability problems.

\section{Descriptions of Coin Activity on Representativeness and Classroom Discussion}

In pair, pre-service teachers were asked to toss a coin four times each, recording the sequence of tails and heads. This activity addressed representativeness bias. Before the toss students were asked to predict the number of tails. Their predictions were written on the board. Most pre-service teachers predicted equal number of tails and heads. Pre-service teachers then wrote their sequences on the board after the experiment. Some of the pre-service teachers found their expected results while others found unexpected results. More than $90 \%$ of the pre-service teachers realized their results contradict their predictions. The pre-service teachers' results support the theory, and provide evidence that all small samples will not resemble the population. However, this activity ended in disagreement since a few pre-service teachers who had their prediction right believe that it will be true with them always. Students should be taken through various activities to test their thinking for development of good probabilistic reasoning.

\section{Descriptions of Activity on Experimental Probability Link to Theoretical Probability and Classroom Discussion}

Pre-service teachers were asked to toss a coin 50 times each, recording the sequence of tails and heads in their workbook. The purpose of this activity is to prove that experimental probability approaches theoretical probability when a coin is tossed a number of times and also addressed representativeness. They were asked to write out their results on the board for discussion. Each preservice teachers were asked to examine her sequence of tails and heads, and whether they can predict the next outcome. However, each pre-service teacher believed they cannot predict the next outcome on the bases of their results. This realization affirms the fact that random events are unpredictable.

Three pre-service teachers Pascaline, Priscilla, and Mavis obtained the following results after tossing a coin 50 times each that attract the attention of the whole class. $\mathrm{H}$ stands for heads and $\mathrm{T}$ stands for tails.

\section{Pascaline : THTHTHHTHTHHTHTTHHTHHTHTTHTHTHTTTTTHTHTHTHTHTHTHTH}

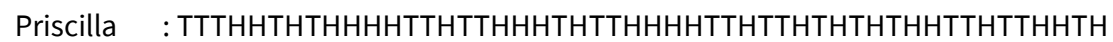

Mavis : :TTHTHTHHTHHTTHTHTHTTHTHHTHHHTTHTHTHTTTHTTHTHTTHTHTH

Pascaline and Mavis' results appear more alternating while Priscilla had 26 heads and 24 tails which was almost even. When asked how they toss the coin to arrive at that results, they said we just tossed the coin we have no idea these would have been our results.

All in all, the pre-service teachers realized that as the number of tosses increases the probability of a head and a tail each approaches 0.5 . And to that extent the experimental probability approaches the theoretical probability. This also emphasizes the law of large numbers. The law of large numbers is a theorem that describes the results of performing the same experiment a large number of times. Based on the law, the mean of the results obtained from a large number of trials should be approximately the expected value. However, the number of times a coin or a die is to be tossed to result in an even number of possible outcome is yet to be derived theoretically.

The class ended with many pre-service teachers appreciating the law of large numbers and its relevance to the theory of probability. However, some pre-service teachers' reactions call for the need to quantify what constitutes a small or large sample. For example, the least number of times a fair coin should be tossed for us to expect the results to approximate the theory.

About $90 \%$ of the pre-service teachers noticed that experimental probability approximates the theoretical probability from a large sample of trials. They recognize that the experimental probability determined from a large sample of trials was proximately equal to the theoretical probability. Similarly, $7 \%$ and $3 \%$ of pre-service teachers are able to recognize when a sample of trials produces an experimental probability that is clearly different from theoretical probability.

\section{Descriptions of Activity for Correcting Equiprobability Bias and Classroom Discussion}

Four students; Mispah, Judith, Sarah, and Emma agree to play a game. It was agreed that two spinners numbered from 1 to 5 each will be spin simultaneously, a person wins when the sum resulted in 4, 6, 7, and 9 respectively. This activity addressed equiprobability bias and belief. When the sum is not 4 or 6 or 7 or 9 , zero is recorded for each of them. The game is played 36 times and the one with the highest score is the winner. The cost for each of them winning is same. Do you think their chances of winning are same or not, and why? Pre-service teachers predicted the chance of each person winning before the start of the game. More than two-third of the participants believe that the chance of winning is same for all. Only two pre-service teachers think that the chance of winning is not same for all but think it depends on who is the luckiest. Five students said they could not tell. After the activity, the teacher organized the whole class discussion around their results. The game was played 36 times by each group consisting of two members. When a sum resulted in 4 or 6 or 7 or 9 , then 1 is recorded in the person's name and 0 for the rest. After the game, the pre-service teachers realized that Judith won more game than Mispah, Sarah, and Emma. It was further noted from many groups' results that Judith won almost twice as Emma. Sarah won more than Mispah and Emma, but the difference between Sarah's and Mispah's results were much closed. Only one group recorded a win for Emma as compared to the other contestants. When asked what accounted for more win for Judith, it was not easily identified by many students at the beginning. With questions and answers the pre-service teachers were able to mention the possible combinations to get a sum of 4, 6, 7, and 9 as

$\{(3,1),(2,2),(1,3)\},\{(5,1),(4,2),(3,3),(2,4),(5,1)\},\{(5,2),(4,3),(3,4),(2,5)\}$, and $\{(5,4),(4,5)\}$ respectively. It was noted how the number of possible combinations translates into the results. The pre-service teachers found that there are many possible ways of getting a sum of 6 as compared to 4,7 , and 9 . There are four possible ways of obtaining the sum of 7 . They further noticed 
that there are three possible ways of getting a sum of 4 . And that only two ways can the sum of 9 be obtained. The pre-service teachers realized this was the reason why Judith won more games than the rest. Also, reflect how Sarah won more games than Mispah and Emma in many groups. However, Emma won in one group. In general, the many possible combinations translate into winning the game. Therefore, in teaching probability teachers need to ask critical questions to keep learners focus else the purpose of teaching probability would be defeated.

Also, another spinner with seven equally divided sectors in which three are black and the rest are red was shown to pre-service teachers and they were asked which colour is the spinner more likely to land without performing the experiment. Almost all the pre-service teachers agreed that the spinner is most likely to land on red sector, with the reason that we have more red sector than black sector. This example addressed equiprobability bias.

\section{Descriptions of a Playing Cards Activity for Probabilistic Reasoning and Classroom Discussions}

A deck of 52 cards is given to pre-service teachers in pair. Most of these pre-service teachers do not have much knowledge about the playing cards. This activity helps pre-service teachers better their probabilistic reasoning. One explanation for this is that many females do not play such games. However, few pre-service teachers were able to give all the necessary information about the cards before they were made to answer questions on them. They were asked to use the cards to answer the following questions. When a card is selected at random, how many situations are involved, if the card selected is a heart or a queen? All the pre-service teachers said there are two ways involved. They mentioned the situations involved as "card selected is a heart", and "a card selected is a queen". However, there are three situations involved. They have to be prompted to mention third situation as "a card which is a queen and a heart". They then compute the probability that the card is a heart or a queen as

$$
\frac{13}{52}+\frac{4}{52}-\frac{1}{52}=\frac{16}{52}=\frac{4}{13}
$$

\section{Descriptions of Food Game Activity and Classroom Discussions}

There are three boxes on a table. The first box (A) contains 9 chocolate cans and 9 milo cans. The second box (B) contains 8 milo cans and 10 chocolate cans. The third box (C) contains 8 chocolate cans and 10 milo cans. This activity promotes better probabilistic reasoning. The milo cans and the chocolate cans are all identical in size and material. In each box the two quantities of the food items have been mixed thoroughly and sealed with the number of chocolate and the number of milo cans written on the box. You are to choose one box which will be opened by a referee. You are then allowed to pick your favorite food item without looking. When you pick your favorite food you win otherwise you lose. Chocolate and Milo which one is your favorite? Pre-service teachers then write their favorite food item. Which of the boxes gives you a better chance of picking your favorite food? And why? In this case the pre-service teachers who preferred milo chose the third box (C) and the pre-service teachers who preferred chocolate chose the second box (B). The students argued that since they have more of their favorite food items in those boxes, their chances of winning are higher with those containers. Interestingly, two pre-service teachers prefer the first box $(A)$ with the reason that none of the food item is their favorite, and which one they pick is good. And since the box $A$ has equal number of chocolate and milo it's fair to choose. When asked which of the food type they wrote as their favorite they indicated none. An indication that when activities are design to reflect real life situations and learners are given the opportunity to explore, they develop correct probabilistic reasoning.

Another example was given to test students' conceptual understanding. Suppose there are three red and two blue pens (all identical in size and material) in a bag. The bag is shaken thoroughly. Belinda closed her eyes, put her hand inside the bag drew out one pen. Is the chance of picking each colour the same? And why? What is the chance that she picks a red pen? The pre-service teachers responded that the chance of picking each colour is not the same. With the reason that the red pens have a higher chance of being picked because we have more red pens than blue pens.

The class realized it's important to consider the implication to opportunities available before making choices in life in order to achieve their goals. They noted that their decision may not necessarily result in the way they consider it fit since there is uncertainty that associate with every opportunity. Pre-service teachers were actively involved in the lesson, and made meaningful contributions. When activities are design for learners to explore and critical questions are asked by the teacher, learners develop a sound reasoning about uncertainties.

\section{Descriptions of Pen Game Activity and Classroom Discussions}

In a group of three, pre-service teachers were asked to pick a pen each from a box without looking, one after the other without replacement. The box contains 6 green, 9 red and 12 blue pens. The object of the game is to pick three colours that are same in a row. For example, if the first person picks a red, the second person picks a red, and the third person also picks a red, then a point of one is recorded for that team, otherwise zero is recorded for the team. One player gets to pick a pen out of the box, the second player, the third player without replacement from same team to win a point. When a team finishes all the pens are collected, put in the box and thoroughly mixed, then the next team comes to pick. Each team will go twenty rounds to see which team has more points. The team with the highest points is the winner.

The results of the groups revealed that the team that picked the blue pen first had a higher chance of getting a point than others. After the activity, the teacher organized the whole class discussion to help them develop a sound reasoning on uncertainties, and also correct equiprobability bias. The chance of winning a point when a red pen was picked first was also higher than the green pen. The pre-service teachers noted that as the first person picked a particular type of pen, the number of that pen reduces, and that also affects the total number of pens in the box. Pre-service teachers' reasoning about "without replacement" situation has been enhanced through this activity. 


\section{Evaluation of the Classroom Observations}

It was very motivating to see every pre-service teachers taking active part in the activities. Pre-service teachers answered questions with much confidence interacting with teaching and learning materials. The pre-service teachers gained much from the lessons through activities, discussions, and questions and answers. My role was to guide them where they test their own belief and misconceptions. The lessons made them correct their own misconceptions and emphasize good probabilistic reasoning. The lessons began from experimental to theoretical to help avoid possible contradiction between the experimental approach and the theoretical. The pre-service teachers were at the centre of the lessons where critical questions were asked by the teacher to dispel their misconceptions. The aim of the critical questions is to keep pre-service teachers focus, and to confront their own belief and misconceptions. Some pre-service teachers said they had learned a great lesson that anytime they are to predict or play a game they have to consider many factors before doing so. This is an indication that students reflect on their thinking if prediction precede the experiment. When problems are well constructed to reflect real life in the form of games, pre-service teachers' probabilistic reasoning are enhanced. It must be noted that if the right questions were not asked at the right time the purpose of the activity maybe defeated since many students enjoyed the activities and forgot to reflect on the results. Many pre-service teachers prefer using contingency tables for listing sample space as compared to a tree diagrams. It was found that rich real life examples and critical questions asked by the teacher help pre-service teachers to better their probabilistic reasoning, and arouse their interest.

\section{RESULTS}

\section{Students' Perceptions of Constructivist Approach of Teaching}

Students' whose reasoning were found to be inconsistent about random event based on the video assessment were given questionnaire to express their view on the lesson. The purpose is to gain insight into how they felt in constructivist classroom. The lesson learnt will help provide direction for effective teaching and learning of probability. From the questionnaire to the participants, these are their responses.

\section{What did you find interesting on learning probability? And why?}

Student 01: "The probability games are very interesting. They demand for good thinking if you really want to win the game. I really enjoy the activities, some of the activities are games I have been playing at home. I learnt from those activities to think carefully about a game before I start to play since all games may not give equal chance of winning."

Student 02: "Probability is very interesting and enjoyable because it demands thinking and analysis of the various possibilities."

\section{What was challenging about probability?}

Student 01: "The understanding of the concept itself and the statement of the question involving probability. It calls for critical thinking and analysis."

Student 02: "Sometimes, how you perceive something to be logical but in probability it's another thing all together. Certain terms in probability are not familiar."

How was your overall experience learning probability at college?

Student 01: “It wasn't easy learning and solving probability problems at all. Because it involves critical analyses. My overall experience learning probability at college, was one of the best experiences ever because my tutor was ever ready to teach us into details. This helped me to develop better understanding of probability."

Student 02: "Probability is very interesting and enjoyable because it demands thinking and analysis of the various possibilities. What I find interesting about probability is the applications in many aspects of our life and having some knowledge on probability will help us to decide on some uncertainties. With all the knowledge on probability, I find it interesting because it helps me make informed judgments on what is likely to happen."

How do you feel going to teach probability at Junior High School (J.H.S)?

Student 01: "Wow, it will be a dream coming to reality, as teaching Mathematics have been my dream. And to teach probability at J.H.S will improve my knowledge on the subject."

Student 02: "On the whole, I feel great and very resourceful and confident since I have been taught well. I also feel very fortunate to provide my pupils with practical experiences on probability."

These comments indicates that constructivist approach to teaching probability motivate and inspire pre-service teachers to apply what they learn. The comments further reveals that probability is a difficulty topic for many students, but if lessons are well 
organize to reflect real life situations, students find it easy to learn. Also, this suggests that pre-service teachers enjoyed learning probability when taught with constructivist approach. The findings of this study confirmed the findings of Prideaux (2007) who conducted a study on the impact of constructivist approach to teaching and learning of Mathematics on conceptual understanding, and found that learners value Mathematics and engage actively in learning the discipline. Similarly, these findings are in agreement with Gurbuz and Birgin (2011) who found student-centered approach of teaching to be effective in addressing probabilistic misconceptions. Furthermore, the findings are in consonance with Roseth, Garfield and Ben-Zvi (2008) who examined the effect of student-centered approach of teaching in classroom teaching, and found that student-centered approach to teaching helps students to have better understanding of statistics.

\section{CONCLUSION AND IMPLICATION}

Based on the findings, it can be concluded that constructivist approach of teaching has positive impact on pre-service teachers' probabilistic reasoning. What this mean is that when teacher educators use constructivist approach of teaching targeting equiprobability bias, representativeness bias, positive and negative recency effects, and belief bias in training teachers, preservice teachers will develop correct probabilistic reasoning and able to reason correctly about probabilistic situations. Also, preservice teachers will be able to teach probability effectively for the conceptual understanding of their learners when they assume the position of a teacher. Additionally, the study also found an emerging question which differ from other studies, which is: What is the least number of times that a coin should be tossed for us to expect the experimental probability to approximate the theoretical probability? The answer to this question will help address representativeness bias among students.

Also, since the activities designed targeting probabilistic misconceptions were found to be effective in the development of preservice teachers' probabilistic reasoning. The study recommend that teachers should:

i. Design and plan activities targeting the probabilistic misconceptions;

ii. Implement the design activities using constructivist approach of teaching;

iii. Ask critical questions to help students to test their own belief and misconceptions;

iv. Reflect and evaluate the teaching and learning processes.

When teaching and learning activities are designed reflecting real life situations and random events in nature focus on misconceptions, students will acquire the needed skills for decision making. Also, when pre-service teachers are at the centre of the teaching and learning process where the teacher serves as a facilitator in the midst of the necessary teaching and learning resources, their correct probabilistic reasoning are developed. In addition, the teacher needs to ask relevant questions to keep students focus, and to confront their own belief, difficulties and misconceptions, and deal with it. Finally, great lessons are learnt when one reflects and evaluates on what transpires in the cause of teaching and learning of probability. What works, how it works, what didn't work, and why it didn't work are identified. The lessons learnt help in better planning and this enhances better probabilistic reasoning of students.

\section{SUGGESTION FOR FURTHER STUDIES}

The pre-service teachers in this study were all females; another study could examine the impact of these activities on gender in relation to probabilistic reasoning. Furthermore, another study can design activities for addressing conjunction fallacy and outcome orientation bias.

Finally, studies can be conducted to examine the probability and statistics content use in training of teachers, and also examine the teaching approaches used in training of teachers to teach statistics and probability units in elementary schools.

\section{REFERENCES}

Ang, L. H., \& Shahrill, M. (2014). Identifying Students' Specific Misconceptions in Learning Probability. International Journal of Probability and Statistics, 3(2), 23-29. https://doi.org/10.5923/j.ijps.20140302.01

Batanero, C., \& Borovcnik, M. (2016). Statistics and Probability for High Schools. Netherlands: Sense Publishers. https://doi.org/10.1007/978-94-6300-624-8

Batanero, C., \& Diaz, C. (2012). Training school teachers to teach probability: reflections and challenges. Chilean Journal of Statistics, 3(1), 3-13.

Gage, J. (2012). Towards a new Probability Curriculum for Secondary Schools. Paper presented at 12th International Congress on Mathematical Education, 8 July-15 July, COEX, Seoul, Korea.

Godino, J., Batanero, C. \& Roa, R. (2001). Training Teachers to Teach Probability. IASE/ISI Satellite, 2001: Juan D. Godino and Carmen Batanero.

Gurbuz, R., \& Birgin, O. (2011). The effect of computer-assisted teaching on remedying misconceptions: The case of the subject “Probability”. Journal Homepage, 58(2012), 931-941. https://doi.org/10.1016/j.compedu.2011.11.005 
Khazanov, L., \& Prado, L. (2010). Correcting Students' Misconceptions about Probability in an Introductory College Statistics Course. Adults Learning Mathematics-An International Journal, 5(1), 23-35.

Liu, Y. (2005). Teachers'Uunderstandings of Probability and Statistical Inference and their Implications for Professional Development (Unpublished doctoral dissertation), Graduate School of Vanderbilt University, Vanderbilt.

Hirsh, L., \& O’Donnell, A. M. (2001). Representativeness in Statistical Reasoning: Identifying and Assessing Misconceptions. Journal of Statistics Education, 9(2), 96-105. https://doi.org/10.1080/10691898.1190655

Prideaux, J. (2007). The constructivist Approach to Mathematics Teaching and the Active Learning Strategies used to Enhance Students Understanding. Mathematical and Computing Sciences Masters. Paper 29. Fisher Digital Publications. Retrieved on 15 June 2019 from http://fisherpub.sjfc.edu/mathcs_etd_masters/29

Rubel, L. H. (2007). Middle school and high school students' probabilistic reasoning on coin tasks. Journal for Research in Mathematics Education, 38(5), 531-556. https://doi.org/10.2307/30034964

Roseth, C. J, Garfield, J. B., \& Ben-Zvi, D. (2008). Collaboration in Learning and Teaching Statistics. Journal of Statistics Education, 16(1), 1069-1898. https://doi.org/10.1080/10691898.2008.11889557

Sharma, S. (2016). Probability from a socio-cultural perspective. Statistics Education Research Journal, 15(2), 126-144. Retrieved on 4 March 2019 from http://iase-web.org/Publications.php?p=SERJ/

Shay, K. (2008). Tracing middle school students' understanding of probability: a longitudinal study (Unpublished Doctoral Dissertation), Rutgers State University of New Jersey. New Brunswick, New Jersey.

Vanderstoep, S. W., \& Johnsonston, D. D. (2009). Research Methods for Everyday Life: Blending Qualitative and Quantitative Approaches. The United States of America: Jossy-Bass.

von Glasersfeld, E. (1995). A constructivist approach to teaching. In L. Steffe, \& J. Gale (Eds.), constructivism in education. Hillsdale, NJ: Erlbaum (pp. 3-15). Retrieved on 25 August 2019 from http://www.vonglasersfeld.com/172 